\title{
AN EXPERIMENTAL DEVICE FOR MEASURING THE SINGLE-PHASE TRANSFORMERS INRUSH CURRENT
}

\author{
L. PETRESCU, E. CAZACU, V. IONIŢĂ, MARIA-CĂTĂLINA PETRESCU \\ University POLITEHNICA of Bucharest, Romania, Faculty of Electrical Engineering, \\ 313, Splaiul Independentei, 060042, district 6, Bucharest ROMANIA, \\ E-mail: lucian.petrescu@upb.ro, emil.cazacu@upb.ro, valentin.ionita@upb.ro, catalina.petrescu@upb.ro
}

\begin{abstract}
Electrical transformers are essential parts of power supply networks and it is important that their life-time to be preserved. The inrush current of this devices could determine malfunctioning of the transformers or even others component of the network. For this reason, determining the inrush current for single-phase transformers is an important issue in power quality analysis of electrical grids. In this paper we presented an experimental device (hardware set-up and software program) that can measure this inrush current features for small transformers (up to $10 \mathrm{kVA}$ ). Also, the device affords the users to measure inrush current knowing the geometry of the transformer, the dimensions and the magnetic characteristic of the core.
\end{abstract}

Keywords: transformer inrush current, experimental device

\section{INTRODUCTION}

Any iron-core transformer absorbs an inrush current when they are instant connected to the power supply grid. This current has a typical waveform characterized by a high amplitude (even 20 time higher than the rated current of the device) and has a single polarity for a few periods until it reaches its state value [1-4]. These inrush currents determine numerous unfavourable effects on the devices and on the power supply network.

The high value of the inrush current may cause electrodynamical and thermal stresses which may determine damaging or malfunctioning of equipments components. In [5-7], the inrush currents are usually divided in different types. This paper investigates only the energizing inrush current which characterised a light loaded iron-core transformer in commutation.

The inrush current is directly influenced by the $B-H$ allure of the magnetic core [8] and especially by the remanence of the magnetic flux density [9-11].

The connection current characteristics are commonly neglected by the electrical equipment manufacturers. Thus, the measure of the inrush current peak value and duration) becomes very significant in conserving the lifetime of a transformer [12].

This paper analyses an experimental device that can measure the connected current of single-phase transformers up to $10 \mathrm{kVA}$. In the following sections we will describe the hardware set-up of the device and the implemented software which will allow users to save measurements, to compare different measurements.

\section{HARDWARE SET-UP FOR THE DEVICE}

The experimental device consists in hardware set-up with the schematic detailed in Figure 1.

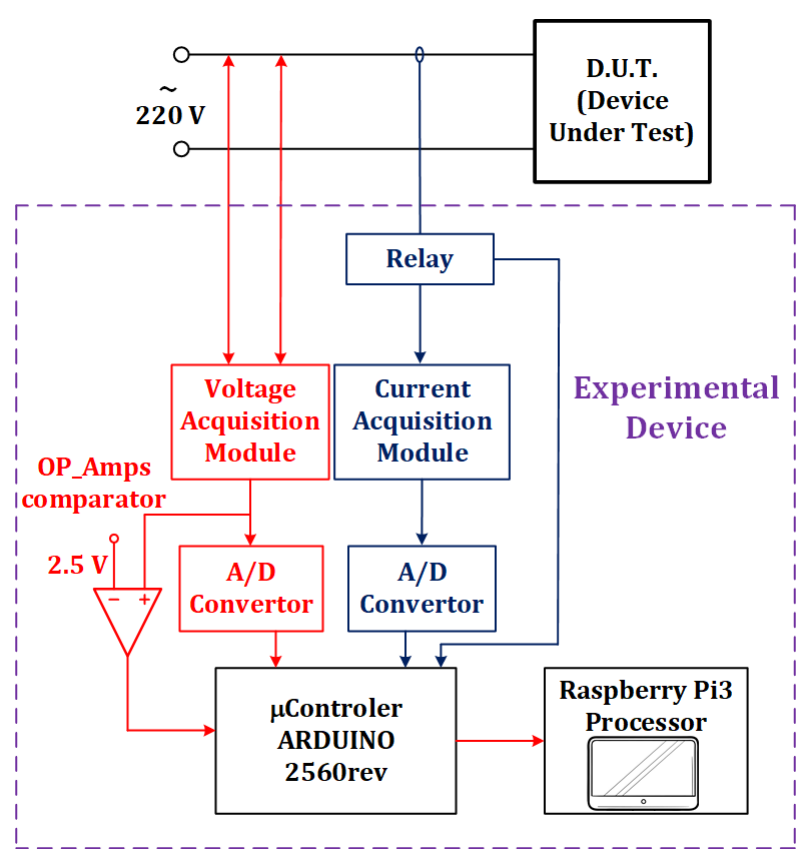

Figure 1. The experimental device scheme.

Starting from this scheme, each module will be presented in the following. First, the relay (Figure 2), ensure that the commutation for the voltage will be made for 0 degrees angle which represents the worst-case scenario for the inrush current [7-10]. Also, this relay can be programmed using the software platform to connect the D.U.T. (Device Under Test) at a particular angle.

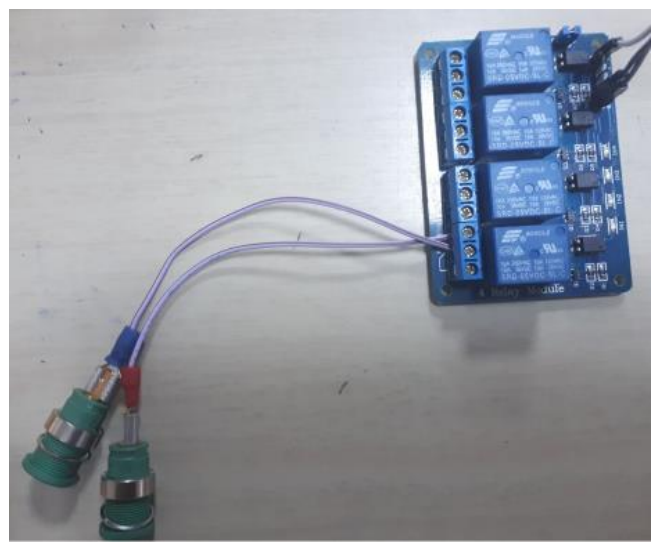

Figure 2. The relay used in the device. 
The electrical signals are acquisitioned using a specific module. Both modules for acquiring current and voltage are detailed in Figure $3-\mathrm{a}$ and $\mathrm{b}$, respectively. The power electrical signals are transformed in analogic signals between 0 and 5 volts using a transformer for the voltage and a shunt for the current [1-3].

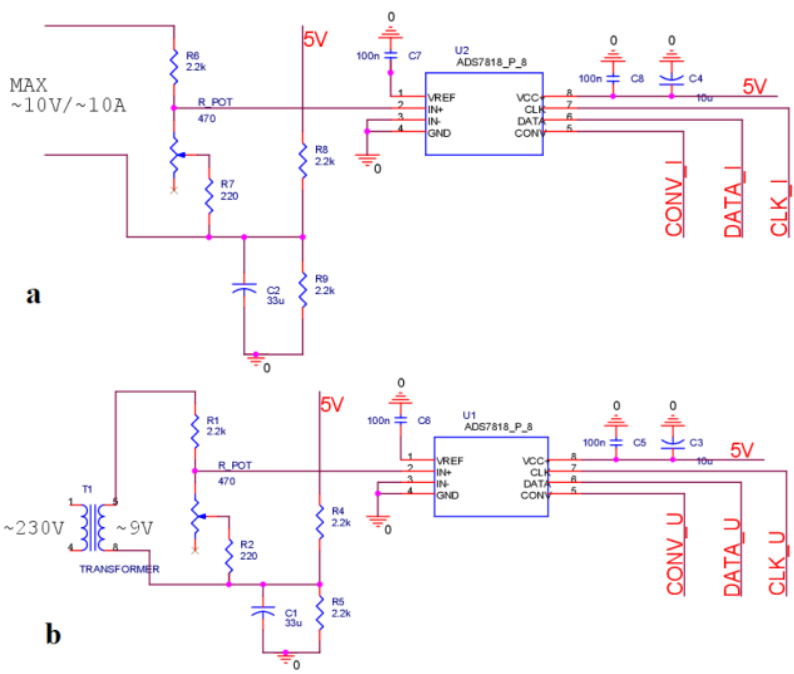

Figure 3. Voltage acquisition module scheme (a) and current acquisition module scheme (b).

Using these electrical schemes, one built the signal acquisitions modules for voltage and current presented in Figure 4.

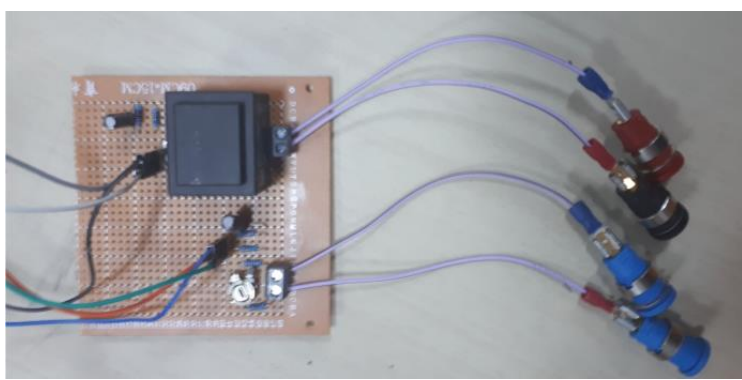

Figure 4. Acquisition module for voltage and current.

Both signals are transmitted to an analogue/digital convertor in order to convert them in $0-4095$ bits digital signals. The A/D converter is presented in Figure 5.

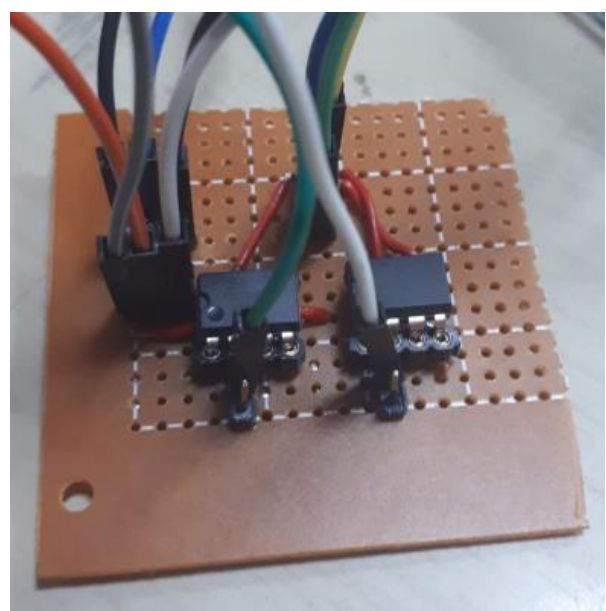

Figure 5. A/D converter for both signals.
All the digital signals are then transferred to an Arduino Mega 2560 rev3 (Figure 6). This is a microcontroller board which has a $16 \mathrm{MHz}$ crystal oscillator, 54 digital output/input pins (14 of them are used as PWM outputs), 4 UARTs (hardware serial ports), 16 analogue inputs, [13].

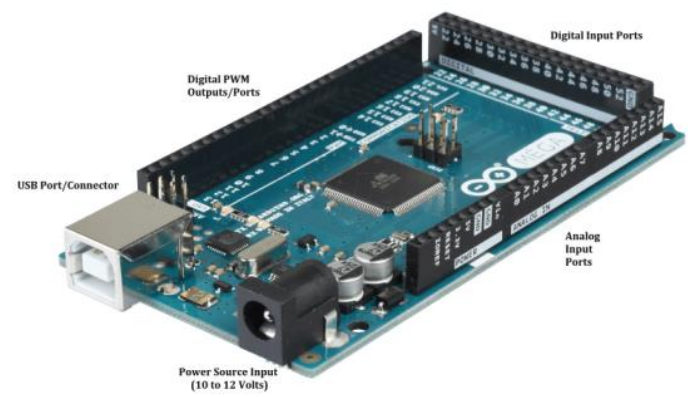

Figure 6. Arduino Mega 2560 rev 3 [13].

The final block of the experimental device consists in a Raspberry Pi3 processor (Figure 7). It has a 64-bit quad core processor $1400 \mathrm{MHz}$, on-board Wi-Fi, Bluetooth and USB boot capabilities which will communicate with the Arduino microcontroller [14]. Also, the remote control is an important function of this processor that will be used in future measurements. The data are transferred to a 7-inch display that will facilitate the access for the users.

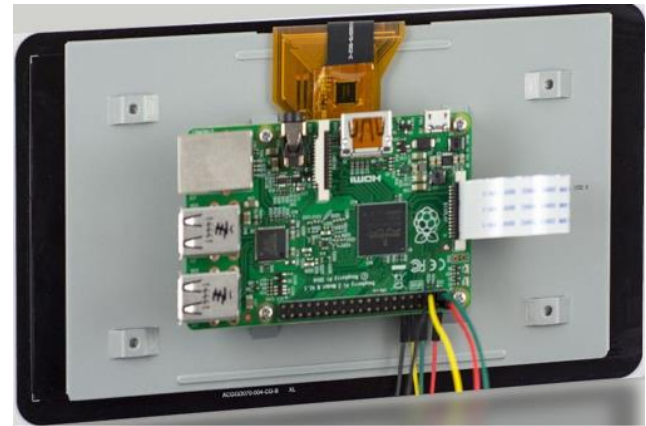

Figure 7. Raspberry Pi3 processor connected with the 7-inch display [14].

The entire experimental device, corresponding to the scheme presented in Figure 1, can be observed in Figure 8 , with the connections between the modules.

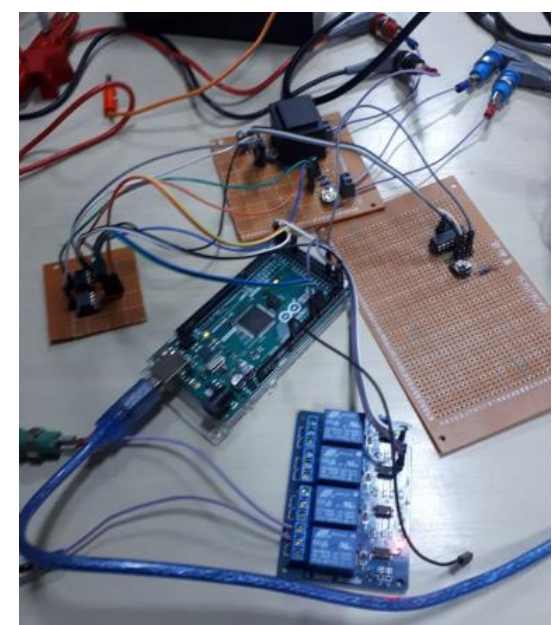

Figure 8. Complete experimental device. 
Finally, the ready to use device was presented in compact form (Figure 9).

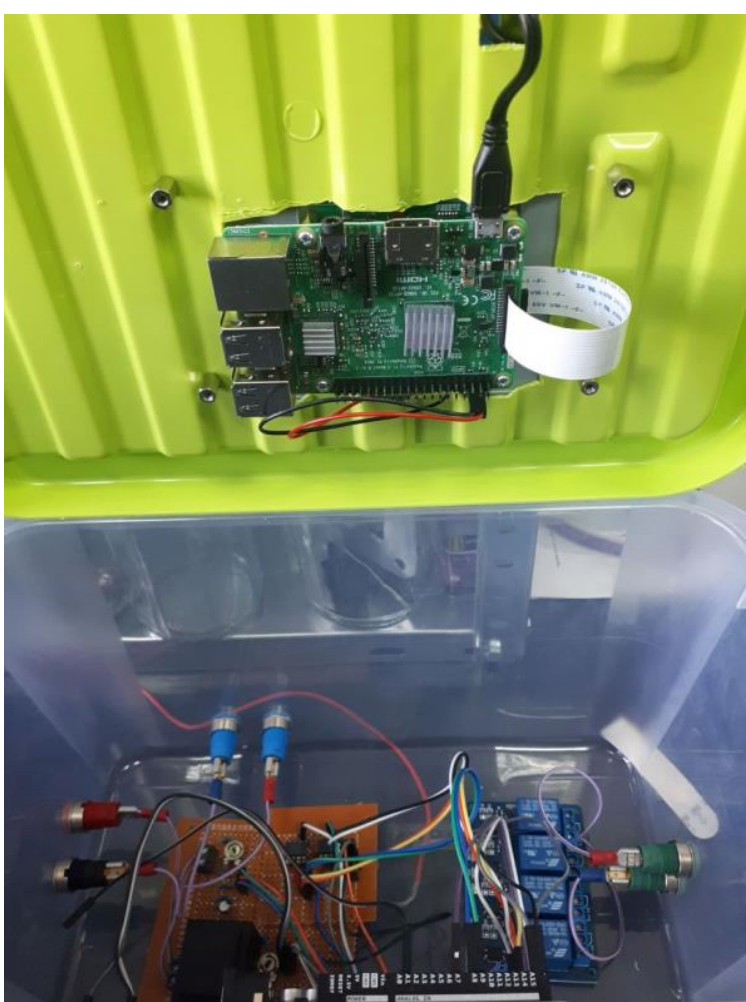

Figure 9. Complete device.

\section{THE DEVELOPED SOFTWARE FOR THE EXPERIMENTAL DEVICE}

An important aspect of the experimental device is the implemented software program which represents the interface between the acquisition module and the users. This was developed in Python programing language [15] due to its versatilities - open source, independent operating system, community-based development (Figure 10).

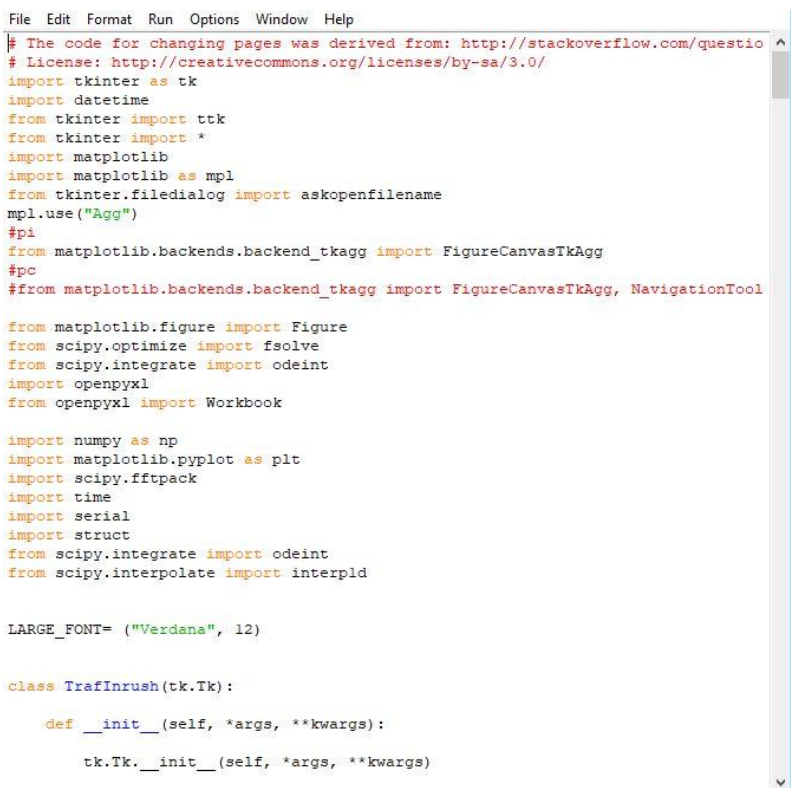

Figure 10. Python capture of the implemented software.
The software has a user-friendly interface with a few windows which are intuitive and allow any user to work and understand the experimental device functionality and operation. The Start Page (Figure 11) offers the possibility of measuring or computing the inrush current, after introduction some nominal parameters of the transformer.

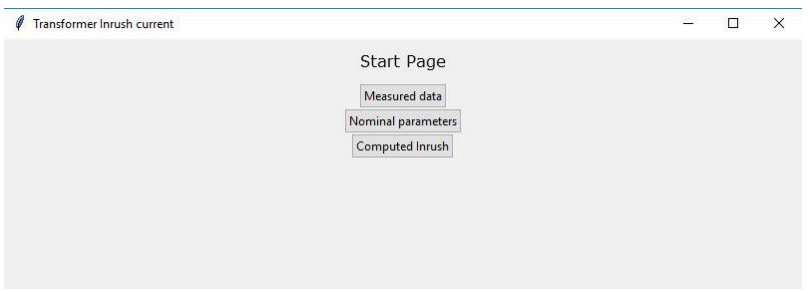

Figure 11. Capture of the Start Page of the software.

Choosing the measuring option facility, a new window is open, and the software allows us to effectuate a measurement (Figure 12). As it can be observed, the results (measured voltage and current waveforms) are presented both in time and frequency domain. The time analysis captures the first 4 periods in order to ensure the reaching of the rated state of the transformer current. The harmonic spectrum shows the first 10 harmonics (this option might be modified if the measuring requires - up to 50 harmonics). The frequency analysis is performed using Fourier transformer only for the first period of each signal.

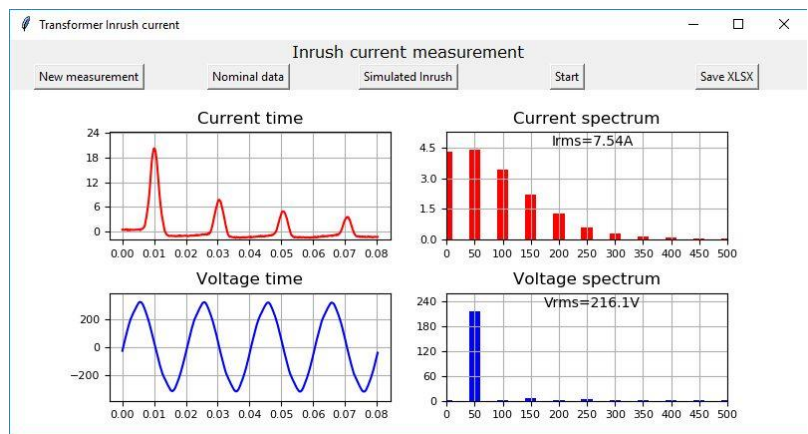

Figure 12. Measuring of the inrush current.

Also, another facility of the software is the calculation of the current and voltage RMS value. After each measurement a picture with time and frequency spectrum is automatically saved, but the program allows user to save the data in an editable version (Excel Document) that might be processed later for different comparative reports (Figure 13). The time domain data has 400 record points which means 100 recorded point for each period of the signals ( $5 \mathrm{kHz}$ sampling). In the frequency spectrum is presented the first ten frequencies of the first period and the RMS values of the signal. 


\begin{tabular}{|c|c|c|c|c|c|c|c|}
\hline 4 & A & B & C & D & E & $\mathrm{F}$ & G \\
\hline 1 & Time & Current & Voltage & & Frequency & Current & Voltage \\
\hline 2 & 0 & 0.463867 & -27.5953 & & 0 & 4.334739 & 1.991125 \\
\hline 3 & 0.0002 & 0.500977 & -7.4097 & & 50 & 4.410132 & 215.9292 \\
\hline 4 & 0.000401 & 0.426758 & 12.39498 & & 100 & 3.416006 & 1.556309 \\
\hline 5 & 0.000601 & 0.371094 & 31.05709 & & 150 & 2.207325 & 6.537465 \\
\hline 6 & 0.000802 & 0.445313 & 49.7192 & & 200 & 1.251597 & 0.596096 \\
\hline 7 & 0.001002 & 0.500977 & 66.66744 & & 250 & 0.590356 & 3.780607 \\
\hline 8 & 0.001203 & 0.575195 & 85.13912 & & 300 & 0.273515 & 0.431859 \\
\hline 9 & 0.001403 & 0.371094 & 104.1821 & & 350 & 0.155412 & 2.022874 \\
\hline 10 & 0.001604 & 0.445313 & 122.0825 & & 400 & 0.096205 & 0.368272 \\
\hline 11 & 0.001804 & 0.31543 & 138.6499 & & 450 & 0.04454 & 0.279545 \\
\hline 12 & 0.002005 & 0.445313 & 154.646 & & 500 & 0.020123 & 0.339633 \\
\hline 13 & 0.002205 & 0.426758 & 170.8325 & & & & \\
\hline 14 & 0.002406 & 0.296875 & 184.9243 & & & & \\
\hline 15 & 0.002606 & 0.408203 & 198.4448 & & & & \\
\hline 16 & 0.002807 & 0.426758 & 209.2993 & & & & \\
\hline 17 & 0.003007 & 0.445313 & 219.5825 & & & & \\
\hline 18 & 0.003208 & 0.389648 & 228.7231 & & & & \\
\hline 19 & 0.003408 & 0.426758 & 240.1489 & & & & \\
\hline 20 & 0.003609 & 0.389648 & 249.2895 & & & & \\
\hline 21 & 0.003809 & 0.426758 & 258.2397 & & & & \\
\hline 22 & 0.00401 & 0.445313 & 267.7612 & & & & \\
\hline 23 & 0.00421 & 0.463867 & 277.4731 & & & & \\
\hline 24 & 0.004411 & 0.445313 & 286.6137 & & & & \\
\hline 25 & 0.004611 & 0.463867 & 293.4692 & & & & \\
\hline 26 & 0.004812 & 0.500977 & 302.0385 & & & & \\
\hline
\end{tabular}

Figure 13. Capture of the Excel Document saved after the measurement.

Finally, the last option offered by the program is to simulate an inrush current. For this part it is necessary to implement the geometric details of the transformer (magnetic length), electric parameters (voltage, frequency, primary winding resistance, windings' turns number) (Figure 14). Also, it is essential in this case to upload a magnetization curve of the core from an Excel file. The current version of the software allows to simulate inrush currents only for E-I core-shape geometries, but in the next version it will permit users to choose the geometry of the device.

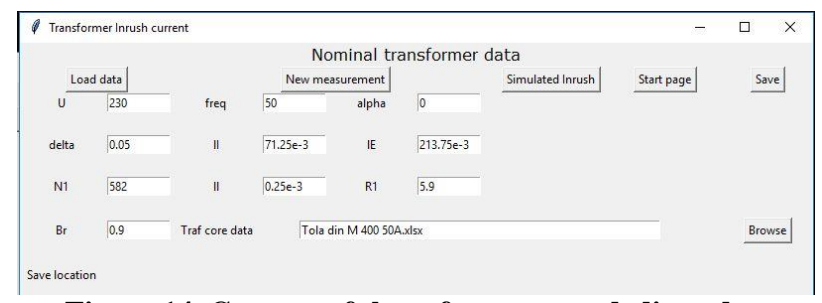

Figure 14. Capture of the software page dedicated to simulated inrush current.

\section{EXPERIMENTAL RESULTS}

The experimental device was tested in laboratory platform (Figure 15) where the D.U.T. was chosen as a single-phase transformer $230 \mathrm{~V} / 24 \mathrm{~V} 400 \mathrm{VA}$ from Eaton [16] (its rated data are presented in Appendix 1).

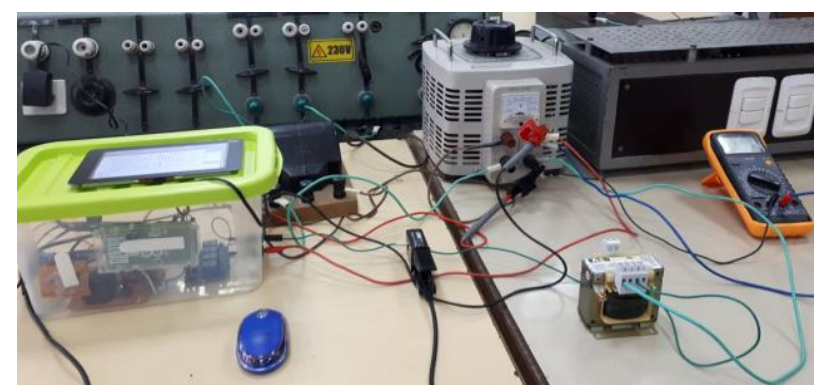

Figure 15. Laboratory platform for testing the experimental device
The tests were performed supplying both the primary and the secondary winding of the transformer. In Figure 16 is presented the inrush current for primary winding (230V) and in Figure 17 is represented for the secondary winding $(24 \mathrm{~V})$.
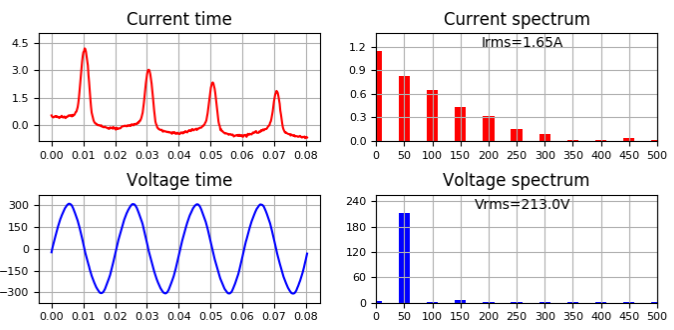

Figure 16. The inrush current for primary winding supplying.
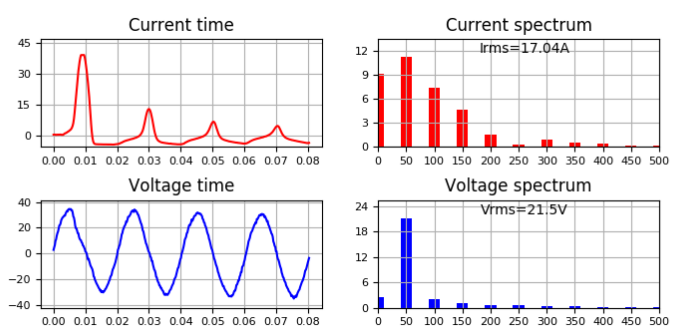

Figure 17. The inrush current for secondary winding supplying.

In both cases the inrush current is analysed, but as it may be remarked for the secondary winding supplying (higher value of the rated current) the peak value of the energizing current is 7-8 time higher than the rated current (for the $4^{\text {th }}$ period).

\section{CONCLUSIONS}

In this paper one presented a mobile experimental device for measuring the inrush current for single-phase transformers up to $10 \mathrm{kVA}$. The device has a hardware set-up describe in Section 2 of the paper. This is realized using a relay, the acquisition modules for the voltage and the current, both signals being transferred to a microcontroller and displayed to the user. In section 3 of the paper is depicted the implemented software which allows to users also to simulate the inrush current for well-known transformers. The depicted assembly of the hardware and the software gave us the experimental device and a sample of inrush current measurement is shown in Section 4.

The experimental device is quite simple, and the cost of the components are not so high, although it proves is limitation due to the low data acquisition speed of the microcontroller. Using a performant oscilloscope could show as better results, but the costs are increased.

Further developments of the device include more geometries options for the simulation part of the software and the possibility for the users to choose the start angle of the voltage (the zero-angle representing the worst-case scenario). 


\section{APPENDIX}

The principal parameters of the inspected transformer are presented in Table 1.

Table 1. Technical data of the analyzed transformer

\begin{tabular}{|l|c|}
\hline Transformer data & Value \\
\hline Rated power $(S n)$ & $400 \mathrm{VA}$ \\
\hline $\begin{array}{l}\text { Rated voltage from the primary } \\
\text { winding }\left(U_{l n}\right)\end{array}$ & $230 \mathrm{~V}$ \\
\hline $\begin{array}{l}\text { Rated voltage from the secondary } \\
\text { winding }\left(U_{2 n}\right)\end{array}$ & $1.88 \mathrm{~A}$ \\
\hline $\begin{array}{l}\text { Rated current in the primary } \\
\text { winding }\left(I_{l n}\right)\end{array}$ & $16.67 \mathrm{~A}$ \\
\hline $\begin{array}{l}\text { Rated current in the secondary } \\
\text { winding }\left(I_{2 n}\right)\end{array}$ & $12 \mathrm{~W}$ \\
\hline No load power losses $\left(P_{0}\right)$ & $27 \mathrm{~W}$ \\
\hline Rated short-circuit losses $\left(P_{s c}\right)$ & $5.3 \%$ \\
\hline The short-circuit voltage $\left(u_{s c}\right)$ & \\
\hline
\end{tabular}

\section{REFERENCES}

[1] Keebler P. F, Gilleskie, R., Inrush currents of electronic ballasts and compact fluorescent lamps affect lighting controls, Conference Record of the 31st Industrial Application Society Annual Meeting, San Diego, 1996, Vol. 4, pp. 2201-2208.

[2] Kislovski, A. S., Fast active inrush current limiter for boost-based resistor emulators, Proc. $16^{\text {th }}$ International Conference on Telecommunications Energy, Vancouver, 1994, pp. 8-16, DOI: 10.1109/INTLEC.1994.396583.

[3] Mallesham, G., Anand, K., Inrush current control of a DC/DC converter using MOSFET, Proc. International Conference on Power Electronics, Drives and Energy Systems, New Delhi, 2006, pp. 1-6, DOI: 10.1109/PEDES.2006.344412.

[4] Cazacu, E., Nemoianu, I.V., Transient state characterization of electronic circuitry small power transformers, Revue Roumaine des Sciences Techniques - Serie Électrotechnique et Énergétique 58(4), 2013, pp. 385-394.

[5] Ling, P. C. Y., Basak, A., Investigation on magnetizing inrush current in single-phase transformer, IEEE Trans. Magn., vol. 24, no. 6, pp. 3217-3222, Nov. 1988, DOI: 10.1109/20.92380.

[6] Lou van der Sluis, Transients in Power Systems, John Wiley \& Sons, Ltd, 2001.

[7] Cazacu, E., Ionita, V., Petrescu, L., An improved method for the inrush current evaluation in single phase power transformers, $20138^{\text {th }}$ International Symposium on Advanced Topics in Electrical Engineering (ATEE), pp. 1-6, DOI: 10.1109/ATEE.2013.6563390.

[8] Cazacu, E., Petrescu, L., Inrush Current Investigation for Single Phase Power Transformers by Means of Magnetic Material Core Characteristics, U.P.B. Sci. Bull., Series C, Vol. 77, Iss. 2, 2015, pp. 193 - 204.
[9] Wang, Y., Abdulsalam, S.G., Xu, W., Analytical formula to estimate the maximum inrush current, IEEE Trans. Power Del., vol. 23, no. 2, pp. 12661268, Nov. 2008, DOI: 10.1109/TPWRD.2008.919153.

[10] E. Cazacu and L. Petrescu, Magnetizing inrush current of low-voltage iron core three phase power reactors, The $16^{\text {th }}$ International Conference on Harmonics and Quality of Power (ICHQP), Bucharest, pp. 843-847, 2014, DOI: 10.1109/ICHQP.2014.6842874.

[11] Ionita, V., Petrescu, L., Magnetic material characterization by open sample measurements, Revue Roumaine des Sciences Techniques - Serie Électrotechnique et Énergétique 54(1), 2009, pp. 8794.

[12] M. G. Vanti, S. L. Bertoli, S. H. L. Cabra, A. G. Geren, Jr., and P. Kuo- Peng, Semianalytic Solution for a Simple Model of Inrush Currents in Transformers, IEEE Trans. Magn., vol. 44, no. 6, pp. 1270-1273, June 2008, DOI: 10.1109/TMAG.2007.916245.

[13] https://www.arduino.cc/en/.

[14] https://www.raspberrypi.org/

[15] https://www.python.org/.

[16] http://www.eaton-electric.ro/ro/. 